\title{
News Networks in Early Modern Europe
}

\author{
Joad Raymond and Noah Moxham
}

Let us begin with a question: what is news?

No one will dispute that the category of news has a degree of transhistorical pertinence. But what do we mean by news - or nouvelles, notizie, noticias, notícias, zeitungen, tijdingen, haber, newyddion? We know what the dictionaries say, but we equally know, from experience, that writing about the history of news, or more commonly writing about particular kinds of news, shares no consensus on a working historical definition. Most of the time it does not matter, because we are happy to run with a loose definition, but then it comes into play in debates about particular forms and about priorities which are affected by definitions - whether a monthly or biannual periodical should feature in histories of newspapers, for example, whether exact periodicity matters, whether issue numbering is an essential. That is to say, the definition of news is contested in discussions about inclusion and exclusion.

This is not an exclusively modern problem. We can see the same paradigms being crossed in Jonson's 1626 play The Staple of News, in an exchange between Cymbal, the entrepreneur who runs the Staple, a news scriptorium, Fitton, his employee, and Penyboy Junior, a gullible customer:

FIT. O Sir! it is the printing we oppose.

CyM. We not forbid that any Newes, be made,

But that 't be printed; for when Newes is printed,

It leaves Sir to be Newes. while 'tis but written -

FIT. Though it be ne're so false, it runnes Newes still.

P. JU. See divers mens opinions! unto some,

The very printing of them, makes the Newes;

That ha'not the heart to beleeve any thing,

But what they see in print. ${ }^{1}$

So what makes something news? Can we even say that it is something recent? Not really, because accounts of early-modern people exchanging news show

1 Ben Jonson, The Staple of Newes, in The Workes of Benjamin Jonson [The second volume] (London, 1631), p. 15.

(C) JOAD RAYMOND AND NOAH MOXHAM, 2016 | DOI 10.1163/9789004277199_002

This is an open access chapter distributed under the terms of the Creative Commons Attribution-

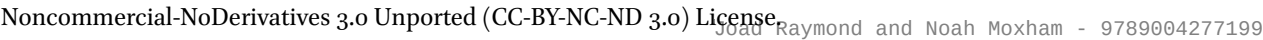


them passing on, and valuing as news, something that is weeks, months, years old, an old sermon or battle, or, significantly, confirming one of two or more earlier, already received, reports; and we recognise that what counts as recent is proportional to distance anyway. Furthermore, as several of the chapters in this collection make plain, news was sometimes more efficiently and speedily transmitted in person than in manuscript or in print, and many forms of written news sought not so much to be the first source of information as to confirm, correct, contextualise or reconfigure news which was already circulating orally. News is as much about the nature of the exchange as it is about the content.

So is it possible to define news? Is it reasonable to ground a definition on a typology of bibliographic criteria, a practice well-represented in the Anglophone tradition, and productively used in Andrew Pettegree's recent history? Or should we look towards a less positivistic list of criteria for what makes a particular event into news, such as the sociologists Galtung and Ruge proposed in the seminal 1973 volume, The Manufacture of News? ${ }^{2}$ This is the kind of move that Gérard Genette makes in Paratexts, where he states that what he offers is "a synchronic and not a diachronic study —an attempt at a general picture, not a history of the paratext". Yet, as Roger Chartier argues in relation to paratexts, this runs the risk of effacing the specificity of the textual configurations, the trade conditions, the technologies, the social formation, the patronage relations that govern the production, appropriation and reception of works in different periods. ${ }^{3} \mathrm{~A}$ similar problem, and certainly a more complicated one, arises in relation to news. In order to write a history of early modern news that is not a reflection of its modern history, we must be attentive-more attentive than a positive definition or a typology of news affords- to the logic and the discontinuities that govern particular exchanges of news.

If we start with a synchronic definition, we treat the thing as an organism with a continuous existence, something that evolves yet retains some degree of identity. The reductio ab absurdum of this can be found in the light-hearted but nonetheless symptomatic chapter headings of Joseph Franks' seminal

2 Andrew Pettegree, The Invention of News: How the World Came to Know Itself (London: Yale University Press, 2014); Johan Galtung and Mari Ruge, 'Structuring and selecting news', in The Manufacture of News: Social Problems, Deviance, and the Mass Media, ed. Stanley Cohen and Jock Young (London: Constable, 1973), pp. 62-72; according to Galtung and Ruge, news is information with a specific quality (up-to-dateness, media transmission, publicity). Cf. Alphons Silbermann, Handbuch der Massenkommunikation und Medienforschung (Berlin: Volker Spiess, 1982).

3 Roger Chartier, The Author's Hand and Printer's Mind, trans. Lydia G. Cochrane (Cambridge: Polity Press, 2014), pp. 135-6. 
1961 book, The Beginnings of the English Newspaper: 'Early Adolescence', 'Growing Pains', 'Coming of Age', 'Maturity'. This work, incidentally, influenced the first part of Jürgen Habermas' Structural Transformation of the Public Sphere, first published in German in 1962, which has cast a shadow, both inspiring and imposing, over histories of news in the Anglophone world since its translation in 1989. Surely Genette would have done better to start with a diachronic (or historical) approach in order to judge which categories have some grip beyond the present, before erecting a synchronic typology that might be no more than an aetiology of the present.

We dwell on this because the problem of definitions and boundaries seems to us to be both a matter of mere convention, to which the most appropriate response might be comfortable indifference, and a fundamental impasse to how an adequate history of news might be written. By adequate here we mean both senses: satisfactory, and fully and exactly representing its object (OED 2, 3b).

We do not only mean that it is hard to write a book about something when you cannot say what it is, but that to write a history of the newspaper, for example, or a history of avvisi; or to write a history of periodicity, or of news pamphlets; or to write a history of diplomatic news communication and so on; is to make a decision about exclusion that probably runs counter to our own working definition of news, one that emphasises flows, continuities, networks, social improvisation. We see passing recognition of this in scholarship on one topic or another that acknowledges the relevance of other modes of news communication while staying sharply focussed; but there is a deeper problem than that, one that emerges from the fundamental inseparability of modes of news communication.

News is essentially connective and dynamic, and resists this kind of compartmentalisation. When we look at a barber shop in a particular street in Venice in $155^{\circ}$, to understand the significance of what is said by the barber to his customer we need to know the position of that barber shop in relation to the Rialto Bridge and St Mark's Square, which, though joined by the Mercerie with its long run of book shops, were distinguished by the different kinds of itinerant vendors who populated them, a distinction codified in periodically issued orders and rules, and by the fact that the former was the economic nervous system of the city, the latter its political heart. But we would also need to know about how news leaked from the city's rich and complex diplomatic network, which received avvisi from the government, and sent in return newsletters from embassies that were transformed into avvisi secreti, which in turn fragmentarily made their way into avvisi pubblici. We would need to know the rules governing the restriction of certain kinds of news to the Council of Ten, the 
Senate, the Great Council and the Inquisitors of State, and how leakage happened. We would need to know the conventions of the oral exchange of news, and we would need to know whether this barber shop was spied upon by those working, directly or indirectly, for the Inquisitors. And it would certainly benefit us to look outside the city, to the different channels of news: who was receiving news from Antwerp, and who from Vienna? Did this piece of news from Constantinople arrive by the faster sea route, passing through Syria then Cyprus before reaching Corfu? Or did it travel more slowly overland towards Ioannina, and then on to Corfu? The question matters because the former route was faster but less reliable, which would factor in the careful weighing of news. ${ }^{4}$ And there are sure to be many other things that we do not yet know that we need to know.

So the difficulty in defining news is not only a matter of common historiographical practice, but also a consequence of the distinctive properties of the thing itself, and these are transferred to its apparently simpler components, such as a newspaper, or a conversation held while having a shave.

One of the most entrenched approaches to managing this excess - and we think management is a useful concept, and an experience that we share with early modern people who participated in some way in the production, distribution and reception of news - is to restrict analysis geographically. 5 The history of news grows out of mid-nineteenth century histories of newspapers, and these earlier histories were embedded in national concerns and nationalist ideology. Though they acknowledged the significance of international news, and sometimes the influence of international models for news dissemination, they emphasised domestic politics, commerce, innovation and readers. The interest in news of the nation, and the need to create a story of news that reflected the spirit or culture of the people-their people-seemed to these early historians to erect as firm a barrier as language. ${ }^{6}$

4 In addition to the chapters by Carnelos and Palazzo in this volume, see Filippo de Vivo, Information and Communication in Venice: Rethinking Early Modern Politics (Oxford: Oxford University Press, 2007); Laura Carnelos, Con libri alla mano: L'editoria di larga diffusione a Venezia tra Sei e Settecento (Milano: Unicopli, 2012); Mario Infelise, Prima dei Giornali: Alle Origini della Pubblica Informazione, secoli XVI e XVII (Rome and Bari: Laterza, 2002), p. 31.

5 A conference on the theme of 'Managing the News in Early Modern Europe' was held at the Huizinga Institute, University of Amsterdam, 18-20 July 2014.

6 Joad Raymond, 'Review Article: The History of Newspapers and the History of Journalism: two disciplines or one?' Media History 5 (1999), pp. 223-32; and Raymond, ed., News Networks in Seventeenth Century Britain and Europe (London: Routledge, 2006), also published as a special double issue of Media History 11.1/2 (April 2005). 
Probably the most important transformation in the recent historiography of news is a changed understanding of the importance of geography. Studies of news media have shifted their focus away from case studies and well-defined histories towards examining transnational connections of news, either by looking at a particular news flow (news exchanged between Constantinople and Venice, or the spread of news of a particular event), or by examining a large body of news (a collection of newsletters, say, or printed periodicals in one or more countries) and finding evidence of, and measuring, the movement of news through areas outside the immediate geography of that source material. In some instances this is supported by quantitative network analysis and other methods developed by STEM subjects (Science, Technology, Engineering and Mathematics). We mean here the research undertaken by the Fuggerzeitungen Project, including Nikolaus Schobesburger and Paola Molina, by Stéphane Haffemayer, Johann Petitjean, Renate Pieper, Virginia Dillon, and others; and, using more traditional humanities methods, Nicholas Brownlees, Brendan Dooley and Nina Lamal.

The full consequences of this research are still being felt for, but it seems to us that a paradigm is shifting in media history, at least as it pertains to the earlymodern period. Defining scope by political (or even theological) geography is no longer plausible, because that geography is artificial and profoundly porous, and because early-modern subjects did not think of communicative geography in those terms. Even in cases where we can point to a concretely expressed wish to restrict access to a network or part of a network - as for instance the limiting of the network of postal relays in fifteenth- and sixteenth-century France to the business of the crown, which envisaged stiff penalties for any breach - we tend to find evidence that these attempts are unsuccessful, and of people managing to obtain access to it; and such semi-enclosed networks in any case themselves depend on other networks. We need to find a way of writing that is not confined to political boundaries, but follows flows. One implication of this is that we need a more complex relationship with political and social history: we cannot rely on narratives, periodisation, units of analysis, and no doubt other things, established in those forms of history for which political geography is a dominant unit.

Adopting the network as a way of conceptualising early modern news allows us to follow flows in precisely this way, while at the same time enabling us to maintain an understanding of news that respects its conceptual integrity; in other words, that does not compel us to view it in strictly developmental terms or, even worse, as an epiphenomenon of a putative march of western political culture towards liberal democracy; that does not enforce separation between the various forms of news and thereby isolate them from the spheres in which they actually functioned; and that allows us to transcend national 
historiographies of news, and to avoid confining early modern news within boundaries which it does not in fact respect. This leads, of course, to some serious practical problems. The history of the media experienced powerful changes towards the end of the twentieth century, when it benefited from a series of interdisciplinary approaches-comprising social history, the history of books and of reading, post-revisionist methodology and so on-which resulted in a much richer approach towards understanding both the social and historical significance and the internal logic of the media. However, the consequence of this was an inevitable centripetal tendency: more detailed studies of smaller topics, in the vein of representative microhistory or material reconstruction (in important work by Ottavia Niccoli, Jason McElligott, David Randall, Filippo de Vivo, and Rosa Salzberg). ${ }^{7}$ How could the archival intensity and attention to minutiae demanded by this kind of work be married with the scope proposed by quantitative analysis and transnational coverage?

It was the prospect of this dilemma that resulted in a 2011 application to the Leverhulme Trust for funding for a research network - though in 2011 the shift towards transnational analysis using quantitative methods was not so evident. The initial proposal defined the network's objective as "to devise methods for analysing news communication across Europe, to identify and address the problems inherent in studying news culture in the microscopic detail that has become necessary in recent years, combined with the geographical and chronological expanse proposed here". The network would spend one year formulating such methods, and a second year testing them. The intention was to "provide a framework for creativity and innovation" that "could be the first stage in a longer-term project through which the news networks of Europe could be comprehensively mapped". The application was successful, and the network was launched with four other core members: Paul Arblaster (then at Zuyd University, Maastricht), André Belo (Université Rennes 2), Carmen Espejo (Universdad de Sevilla) and Mario Infelise (Universita Ca' Foscari, Venezia), and Noah Moxham as administrator (replaced by Lizzy Williamson in the spring of 2013). These were joined by another 29 scholars at our five workshops, and more at the London conference in July 2013.

In 2011 the proposal (and proposer) envisaged that the range of methods developed would essentially involve a range of ways of making case studies

7 For example: Ottavia Niccoli, Prophecy and People in Renaissance Italy, trans. Lydia G. Cochrane (Princeton: Princeton University Press, 1990); Jason McElligott, Royalism, Print and Censorship in Revolutionary England (Woodbridge: Boydell, 2007); David Randall, Credibility in Elizabethan and Early Stuart Military News (London: Pickering and Chatto, 2008); de Vivo, Information and Communication; Rosa Salzberg, Ephemeral City: Cheap Print and Urban Culture in Renaissance Venice (Manchester: Manchester University Press, 2014).

8 Application submitted to the Leverhulme Trust by Raymond, 21 March 2011. 
interlock and identifying mathematically convincing ways of scaling up case studies. This is not what happened: essentially the network saw that our own communication needed to be erected upon a clearer grasp of the linguistic foundations of our exchanges (see Chapter 3 ), and from there we moved towards defining the institutions and the patterns of communication that shaped those foundations. The conflict that arose here was productive, because when we absorbed new case studies, we did so within ongoing contestation about the larger picture within which they should be assessed. In other words the rolling debate of the network, which reflected in its organisation the earlymodern news network that we were studying, provided a guarantee that we would be engaged with minutiae and the broad sweep at the same time. With this dynamic the collaboration took its own direction. After two years we arrived at a series of more or less consensual lessons. They are here presented as nine propositions, with the caveat that this summary of a collective outcome reflects the view from a single node within the network.

(i) Between $145^{\circ}$ and $165^{\circ}$ an international news network developed, which was not the product of any single country or set of institutions

There was a series of parallel evolutionary processes in the news media in many European countries, often temporally close, not necessarily involving direct influence. This happened because of transnational communication networks: the emergence of news media in print and manuscript in any given place was the local manifestation of an international exchange not limited to any one medium.

One way of demonstrating the existence of this network was through the research of those who were challenging the old geographies of news. Numerous scholars have been drawn to analysing the movement of news stories in time and space. This is possible because of the conventions observed by those who relayed news in writing. This is most apparent in the way that the paragraph of news worked. Paragraphs characteristically contained indicators of the place and date not only of the news item, but of the place or places where the news originated or was relayed. This data was retained through subsequent transmissions, and when the news moved between languages or between forms. The logic of the paragraph as an instrument of news technology has been insightfully captured by Will Slauter. ${ }^{9}$ At the same time several scholars simultaneously yet independently developed means of tagging date and place data in paragraphs, and exploring

9 Will Slauter, 'Le paragraphe mobile: circulation et transformation des informations dans le monde atlantique du 18e siècle', and 'The Paragraph as Information Technology. How News Traveled in the Eighteenth-Century Atlantic World', Annales: Histoire, Sciences Sociales, 67 (2012), pp. 253-78, 363-89. 
thereby the spread of sources for a news publication, and the time intervals between events and the stages of their transmission. These include Johann Petitjean; the work of the Fuggerzeitungen project, directed by Katrin Keller in Vienna, including powerful data mapping by Nikolaus Schobesberger; Virginia Dillon's work on the spread of news about Gábor Bethlen and the two Rákóczis in Transylvania; Chiara Palazzo on the spread of the news of the battle of Chaldiran in 1514, work showing the importance of Cyprus in the entry of news from the Ottoman Empire into the Venetian and hence the Europe-wide news network; the present co-author Joad Raymond's work on the reception of Milton's polemics in the 165os; Massimo Petta on the standardisation of printed avvisi; Carmen Espejo on the movement of news between the extremes of Europe, Transylvania and Seville; Javier Díaz Noci on Spain's connections with Europe and with America; and Stéphane Haffemayer, in his extraordinarily meticulous analysis of international news based on the Paris Gazette in the 1680s. ${ }^{10}$

These are just a few examples of the ways in which networks - and we hope it is becoming apparent that we mean by network not only a number of people in contact but also the narrower sense of a complex and dynamic system." These scholars use innovative methodologies to be very precise about the movement of news, and these precise conclusions need to and can displace the old generalisations, to which they very often run counter.

To understand how the network came into existence, and why it takes the shapes it does, it is necessary to understand the role of diplomats, the postal service, and cities.

(ii) Diplomatic channels constitute the original news networks, and determine the form of communication

The avviso (or aviso) form developed as a means of communicating with resident diplomats. Diplomatic missions were a significant means of relaying news, both to home and to communities in exile, and indeed to the host

10 See the contributions of these scholars to the present volume, and, in addition: Johann Petitjean, L'intelligence des choses: une histoire de l'information entre Italie et Méditerranée, $X V I^{e}-X V I I^{e}$ siècle (Rome: Ecole française de Rome, 2013); <fuggerzeitungen.univie.ac.at/> $(2 / 2 / 15)$; Virginia Dillon, 'News of Transylvania in the German Printed Periodicals of the Seventeenth Century, from István Bocskai to György II Rákóczi', DPhil thesis (University of Oxford, 2014); Chiara Palazzo, 'Nuove d'Europa e di Levante. Il network veneziano dell'informazione nella prima età moderna. 1490-1520', PhD thesis (Università Ca' Foscari, Venezia, 2012); Raymond, work forthcoming in vol. 7 of the Oxford Complete Works ofJohn Milton; Haffemayer, 'La Gazette en 1683-1685-1689: analyse d'un système d'information', Le Temps des médias, 20 (2013), pp. 32-46, and also his L'information dans la France du XVIIe siècle: la Gazette de Renaudot (1647-1663) (Paris: Honoré Champion, 2002).

11 See Ch. 3, below. 
country. Both host and visitors needed to exploit news effects-spin and propaganda, to use anachronistic terms - in order to conduct their business. Moreover, resident ambassadors formed important nexuses in webs of communication. They were integral, for example, as the Venetian state archives reveal, to the way the Venetian Maggior Consiglio gathered the news that dictated its foreign policy. The basic periodical form of the period developed out of the conventions of diplomatic newsmongering into regular newsletters. These arvisi somari emerge in the late fifteenth century out of the weekly despatches sent by ambassadors. These were essentially secret documents, but the communication network was a leaky one, and informed broader social groups. It was the original reports - not the digests into avvisi- that were the earliest forms of printed news; these were then joined by other kinds of letters, until the trade in occasional pamphlets of news was widespread by the late sixteenth century. As Tracey Sowerby demonstrates in her chapter on the Elizabethan diplomatic network, the flow of news through the ambassadorial community was also essential to its smooth functioning; news was currency, and in order to obtain a worthwhile stream of information to send back to the home court an ambassador needed news of his own to supply in exchange.

(iii) Cultures of managing news, including the linguistic management of news, followed the network

This is an occasion to mention the dangers of faux amis. From the start the network members had to exorcise some lexicological ghosts. Mainly working within the romance languages, we shared a vocabulary; a commonality only intensified by the fact that the terms for news and news forms spread across Europe with the news itself. However, international vocabularies were inflected by local circumstances, and produced a series of false friends. Avviso and avvisi were nearuniversal terms. But in Italy they were generic terms describing an object and the news-content, and it was necessary to distinguish between avvisi secreti and avvisi pubblici. In Spanish, however, this distinction did not apply: moreover, an aviso was a single information unit; hence the formulation relación de avisos or carta de avisos to describe the material form containing the information units. In Portuguese the word carried more of the freight of its older etymology and meant circulating news and opinion, moral advice and so on. Meanwhile in Dutch advijs implied foreign origins, and was used to describe the object (and in titles, unlike the Spanish); and in English avisoes was used to describe news publications without this formal specificity (and by the eighteenth century, began to be used metonymically for a despatch boat). This resulted in some confusion. Even this is a simplification, as it overlooks semantic change, which could occur rapidly - the cultural associations of words sometimes shifted from year to year. 
As they were imported into a language, new terminologies of news often indicated the inherently and distinctively foreign aspect of news; and in certain cases the attributes denoted by the adoption of a particular term in a new linguistic context refer to the language and news culture which are its proximate sources, and not to the actual origin of the term. Thus the term gazeta, when first adopted in Portugal in the 1640 s, takes it for granted that a gazette is a printed news form and has Renaudot's printed French Gazette as its immediate reference point rather than the manuscript gazette of Venice from which Renaudot adopted the word, a point reinforced by the later emergence of gazetas de mão in Portuguese to describe manuscript newsletters.

So the linguistic medley reflected the nature of the news network; it was fundamentally international, but subject to the transformative influences of local culture; and the local ramifications of the international network then fed back into it. Another striking homology across much of Europe involves the granting of print-distribution privileges to guilds of blind men: in Madrid, for example, the guild of blind men held a quasi-monopoly over commercial news 1605 to 1637; in a 1611 dictionary Sebastián de Covarrubias defined "cartanova en lengua Valenciana" as "las coplas, or relacion en prosa de algun successo nuevo y notable, que los ciegos y los charlatanes y salta en vanco, venden por las calles y las plaças" "cartanova in the Valencian tongue [means] the verse or prose relation of news events that are new and noteworthy, which the blind men, charlatans and street performers sell on the streets and in the squares"); and in the late eighteenth century a local newspaper was entitled Correo de los ciegos de Madrid. In Lisbon the blind fraternity had a similar privilege, and in Venice there was a close relationship between the formal guild of blind men and the distribution of news; and across Italy singers of ballads were often blind. ${ }^{12}$ In this case not the language but the practice of news management spread in a surprising way that cannot be ascribed solely to function.

(iv) (a) Postal routes formed the spine of news communication, shaping all printed and manuscript forms that follow, including periodicity

Complementing the diplomatic network, and remaining in place when the significance of that network had diminished, the post, initially official and

12 See the chapters by Carnelos and Díaz Noci in this volume; Sebastián de Covarrubias, Tesoro de la Lengua castellana ó española (Madrid, 1611), fo. 206r; <hemerotecadigital.bne.es/details. vm?q=id:0003752667\&lang=es> [2/1/15]; see also Rosa Salzberg, 'Print Peddling and Urban Culture in Renaissance Italy', in Not Dead Things: The Dissemination of Popular Print in Britain, Italy, and the Low Countries, 1500-19oo, ed. Roeland Harms, Joad Raymond and Jeroen Salman (Leiden: Brill, 2013), at pp. 43-4; we are also indebted to communications with Javier Díaz Noci. 
subsequently commercial, was the most important basis for the geography, speed and economics of news dissemination. Wolfgang Behringer and Paul Arblaster had already insisted on the importance of postal networks for the temporality and geography of news. ${ }^{13}$ News followed postal and carrier routesof course it did, though not exclusively. There were several postal networks: the Taxis system in the Holy Roman Empire, a separate one established by the Taxis in Spain, the English and French postal systems, the system centred on Antwerp, the various systems in the Italian city states, and more. In certain well-known cases the postmasters themselves were newsagents (the first Swedish printed newspaper, for instance, the Ordinari Post Tijdender, was based on reports gathered by the post-masters); as Nikolaus Schobesberger demonstrates in his analysis of the origin points and distribution routes of the Fugger newsletters, the postal route could actually function as an instrument of news-gathering across borders, with newsletters commissioned by Philip and Octavian Secundus Fugger being compiled serially by the addition of news at each major entrepot on the road to Augsburg. Post-masters and -mistresses could also work as state agents by searching posts, thus facilitating the transfer of news from one mode into another, and causing those who preferred secrecy to improvise means, including codes and ciphers, to circumvent this constraint. ${ }^{14}$

(iv) (b) News moved freely between various regional postal routes, enabling pan-European communication

These postal routes were interconnected, and there were means of sending letters and packets that jumped from one system to another. It was possible to send a letter from Venice to Exeter. Postal systems have an arterial function within news networks; they are a necessary though not sufficient foundation of periodical news, and determine its periodicity. The shape of the postal networks, and the effectiveness of the movement across apparently discrete systems, can be confirmed by the actual movement of news, as detected, for example, in reception. This is an important general point for the understanding of news networks, and one that historians should remain mindful of, since it reflects the challenges we face in trying to describe to articulate fully its structure and function- that

13 Wolfgang Behringer, 'Communications Revolutions: A Historiographical Concept', German History, 24.3 (2006), pp. 333-74 and Im Zeichen des Merkur: Reichspost und Kommunikationsrevolution in der Frühen Neuzeit (Göttingen: Vandenhoeck \& Ruprecht, 2003); Paul Arblaster, 'Posts, newsletters, newspapers: England in a European system of communications', in News Networks in Seventeenth Century Britain and Europe, ed. Raymond, pp. 19-34.

14 Nadine Akkerman, 'The Postmistress, the Diplomat, and a Black Chamber?: Alexandrine of Taxis, Sir Balthazar Gerbier and the Power of Postal Control', in Diplomacy and Early Modern Culture, ed. Robyn Adams and Rosanna Cox (Basingstoke: Palgrave, 2011), pp. 172-88. 
the network was exploitable by contemporary actors without necessarily being fully apprehensible. It was not necessary to know every node of the network, or every means of transmission that news would pass through to transmit it successfully from Aachen to Zurich. This fact is also a further indication of the conceptual limitations of microhistorical approaches to the history of news.

(iv) (c) The speed of news depended on the speed and frequency of the post or carrier

The velocity of news can be calculated anecdotally but also more systematically by using the archives of post offices and the franking of the documents that travelled by post; and by measures of the speed of horses and estimates of miles travelled per hour. Such studies are exceptionally useful. However, post is not simply a measure of geography against time, and additional factors shaped the temporality of the post, beyond its raw speed.

One of the newsletter writer Joseph Mead's sources was James Meddus, the rector of St Gabriel Fenchurch. Writing from London, Meddus supplied a good deal of Mead's foreign news, probably from the Exchange. Meddus sent Mead news by the ordinary weekly carrier, probably from the Black Bull on Bishopsgate, and the carrier travelled over Friday night. The arrival on Saturday, however, was too late for the inclusion of this news in Mead's letter to Sir Martin Stuteville, because the carrier from Cambridge to Dalham, where Stuteville lived, also left on Saturday morning. Hence al though the journey was under 18 miles, and could easily be walked in a day, the inconvenience of mere hours meant that Dalham received some news a week later. This is what it means to be on the periphery. ${ }^{15}$

A similar example can be found in the case Nicolas-Claude Fabri de Peiresc, a scholar in Aix-en-Provence, who worked out by careful calculation based on the speed and frequency of the post, and the speed at which news reached Lyon, that Renaudot was lying on the date of his gazette, and that it was in fact published on a Friday and not on the Saturday advertised, and that therefore Renaudot was perfectly capable of getting it to him a week earlier. ${ }^{16}$

(v) Metropolitan centres are essential to the functioning of the network

The above points lead towards this fifth: the importance of entrepôts. News clearly moved between various parts of the network, but also between various forms in cities.

15 See Ch. 24, below.

16 See Ch. 16, below. 
We can begin to understand the whole of Europe's networks by analysing the varied constitution of entrepôts. The social, urban and commercial topography of Venice has been opened up for us in quite brilliant detail by Filippo de Vivo and Laura Carnelos. We have less exhaustive accounts of London, Antwerp and Paris already. Looking at centres, at the volume and speed of communication among them, the chronologies by which seriality and periodicity and other practices such as printing evolved in them, we can work towards the reconstruction of a network that was greater than any of the media that we conventionally study.

News travels between and is relayed by entrepôts, and it is within these that units of news are recombined into various aggregates. Translators congregate in cities and form relationships with scribes and printers, and thus provide the means by which a news item shifts from one language to another, which sometimes means shifting from one set of network connections to another. It moves between forms - word of mouth, manuscript and print - and also into the various forms and genres. These systems of aggregation are local as well as transnational, of course, drawing in local news from a surrounding catchment area and loading it onto the international network as well as retransmitting international news. The local transforms the international, and the conditions for how the international is experienced are local; the international news network extends from Stockholm to Lisbon, but it looks different from those two places.

Similarly with the printing of news. For many historians of the news-as for Penyboy Junior - the shift to printing represents the apogee of the newsiness of news, because it is when it is printed that news receives that step-change in publicness that grants it the ability to affect crowds, influence politics, and shape debates in the public sphere. The printing of news takes place within the network, as one of the consequences of this network, when certain circumstances converge. And the politics and economics of a particular urban centre is one of those circumstances: so the printing of news takes place at the intersection between local conditions and quite possibly unrelated transnational networks. The printing of news happens at specific moments, and we need to see its chronology in that way. This is not to deny that the printing of news is important - the effects may be more important than the causes. But it is not the way to understand the life of news.

There is obviously a great deal more to be said about cities and the way they work. But one general conclusion we can draw is that the geographical consciousness that we do find in early modern news culture is one that reflects the major entrepôts of news, the shifting balances between them, and the ways in which they are connected. 
(vi) state censorship is practised in international contexts

Among the ways in which local circumstances transformed an international network was through censorship. The circumstances for the production and distribution of manuscript newsletters and printed news, and particularly the interrelations among this production and distribution and the state vary from place to place. To understand the comparative history of censorship in various countries, however, we need more than a series of correspondences with varying dates and relative importance; it is no more a simple matter of translation than understanding the lexicons of news. The conceptual underpinnings of censorship were very different in the Habsburg Netherlands from Portugal from the Italian city states from Britain. Even so, states examined each other's censorship practices partly in order more effectively to undertake their own. There is in fact a long-term history of international diplomatic co-operation in censorship. ${ }^{17}$ And, to add an extra layer of complexity, the proximity of other countries where censorship operates differently, and can be used to evade local restrictions, shapes transnational communications and exchanges. To use perhaps the most obvious example: the fact that there were alternative printing centres in the Low Countries not subject to English or Scottish law shaped the development of the war in the British Isles at several points between 1637 and 1660 - it was a war of three kingdoms plus an indiscreet republican neighbour. ${ }^{18}$ So censorship is more important than we have recognised, though not because it was more effective: indeed there is plenty of evidence from numerous political and theological jurisdictions that many key figures and pioneers in the development of early modern news media worked to a significant extent within the apparatus of state, whether with tacit or official permission or with privileged access to information. It is important because the international network is modified locally, and because local circumstances shape the international network elsewhere.

(vii) Centre and periphery are products of patterns of communication as much as of geography

Peripheries are relational. Two points.

As we have suggested, to be in Dalham is to be on the periphery; and in a sense to be in Britain is also to be on a periphery, in part because Britain is the

17 See Joad Raymond, 'Les libelles internationaux à la période moderne : étude préliminaire', Études Épistémè, 26 (2014), <episteme.revues.org./297> [2/2/15].

18 Raymond, Pamphlets and Pamphleteering in Early Modern Britain (Cambridge: Cambridge University Press, 2003), 161-201. 
end of a network. News seldom went from there to anywhere else. This matters for a number of reasons. One is that a city like Lisbon was both connected to and remote from the centres of European modernisation and yet it was the major inlet for news from the new world, thus providing an essential connection between Europe and the rest of the world. Ragusa (modern Dubrovnik), Venice, and Strasbourg have importantly complicated roles in terms of the mismatch between their physical and their cultural or political centrality, and the development of patterns of news communication across Europe is influenced by this mismatch. In that sense Strasbourg's position in the history of news remains in some sense inexplicable-in that its status as the site of the first printed newspaper contrasts with its relatively inconsequential position within the European communications network. This might act as a further warning against the danger of privileging the printed newspaper in the historiography of news.

Secondly, accounts of speeds of transmission show that news slows significantly across certain areas, such as east of the line between Venice, Vienna and Krakow. And in some relationships there is an assymetry in interest in news: Constantinople is a source of great fascination for western Europe, but the relationship is not fully reciprocated.

So it seems that news networks, though they are fundamentally connective, experienced and enhanced or even created boundaries, constituted peripheries as well as centres.

\section{Conclusion}

These, then, were the shared lessons of the research network. They represent a mixture of the methodological and the empirical, and the basis of a history without constituting that history itself, or even a precise manifesto of how these foundations should be built upon. The scale of the enterprise remains the most difficult challenge and the richest opportunity. To write this history on anything less than a European scale is to ignore the phenomena that gave national news its shape. A national history, or a series of case studies of international news, risks examining only the local inflections and modulations and transformations of a fundamentally international system. It is not merely the case that international news is important locally: the news system is itself an essentially international phenomenon, and local manifestations of it effect only local and relatively minor variations. This international system has its own life and rationale: it is much more than the aggregate of its local manifestations, and this is a reason why individual studies have failed to result in a new big picture to replace that we have inherited from the historians of the mid nineteenth century. 
We argue that the present volume demonstrates the fundamental importance of the European network as a conceptual framework for the history of news. Such a conception provides a matrix which can productively hold together without falsification many different aspects and instantiations of early modern news - forms, languages and lexicons, genres, uses, responses, particular flows, agents, and events. It is also crucial precisely because it can usefully accommodate case studies, and even depends upon them; it legitimates them in turn by changing the relationship of part to whole, and by not insisting that the part do duty for the whole. The European news network cannot be explained solely in terms of the spread of forms of news, nor in terms of physical infrastructure; it is partly constituted by, among many other groups, young aristocratic travellers, or by exiled religious communities, or by natural philosophers eager for news of the latest discoveries. All of these subsidiary networks, whose structure can only be apprehended at a microhistoric level, also inform our understanding of the wider network, from which they are not separable.

This understanding of feedback helped resolve prolonged debates about the structure of this volume. The 37 essays could have been separated and ordered in various ways. At first it seemed that the most obvious was to divide theories and methods from case studies, and to divide the former into themes: spaceforms-uses, perhaps. More abstract conceptual divisions might have worked too: locales-connections-boundaries, for example. The present scheme seeks to integrate some of the processes of the project into its legacy. It begins with accounts of networks and network analysis as a means of understanding the pan-European history of news, and in particular with a pair of synthetic, collaboratively-authored essays, one on the emergence of the early modern postal networks that moved and shaped news and another that lays out the development and spread of the lexicon of news in several important European vernaculars; it moves on to a section on 'modes', that looks at particular forms of news communication, and constitutive elements of those forms; and thence to case studies that articulate parts of the network not apprehensible from too far away, but which remain essential to its function. By this means we could embrace, without reducing to a one-size-fits-all model, the fundamental connectedness between the transnational, the national and the local, and between the many modes in which news communication was experienced. And the order of case-studies? They are arranged not temporally but longitudinally, from west to east. 